Article

\title{
The Afro-Oriental Genus Yaeprimus Sasa et Suzuki (Diptera: Chironomidae: Chironomini): Phylogeny, New Species and Expanded Diagnoses
}

\author{
Wu Han ${ }^{1,+} \mathbb{D}$, Jinxing Wei ${ }^{1,+}$, Xiaolong Lin $^{2} \mathbb{D}$ and Hongqu Tang ${ }^{3, *(\mathbb{D}}$ \\ 1 Research Centre of Hydrobiology, Jinan University, Guangzhou 510632, China; \\ hanwuwu621@gmail.com (W.H.); weijinxing90@163.com (J.W.) \\ 2 College of Life Sciences, Nankai University, Tianjin 300071, China; lin880224@gmail.com \\ 3 Institute of Groundwater and Earth Science, Jinan University, Guangzhou 510632, China \\ * Correspondence: townningt@gmail.com or thqtang@jnu.edu.cn \\ + These two authors contributed equally to this work.
}

http://zoobank.org/urn:lsid:zoobank.org:act:CB1AE353-3876-4E23-AEE3-DBBEAA5D54A6

Received: 9 December 2019; Accepted: 13 January 2020; Published: 15 January 2020

\begin{abstract}
Expanded generic diagnoses of all life stages of Yaeprimus Sasa et Suzuki, 2000 (Lunditendipes Harrison, 2000, syn. n.) are given. Yaeprimus tropicus comb. n. is redescribed as an adult based on type material. Additionally, a new species Y. balteatus sp. $\mathbf{n}$. from Oriental China is described based on the adult male and pupa. The phylogenetic position of Yaeprimus within Chironomini and the validity of the new species are explored based on concatenated five genetic markers $(18 S, 28 S$, $C A D 1, C A D 4$, and COI-3P) through both mixed-model Bayesian inference and maximum likelihood methods. The results strongly support Yaeprimus as sister to Imparipecten Freeman, 1961, which counters a previously proposed systematical position based solely on morphology.
\end{abstract}

Keywords: Yaeprimus; Lunditendipes; synonymy; new species; phylogeny; Asia; Africa

\section{Introduction}

Yaeprimus Sasa et Suzuki, 2000, was established based on adult males of Yaeprimus isigaabeus Sasa et Suzuki [1] collected from Ishigaki Island in Japan. Subsequently, it was revised in detail of all stages by Yamamoto and Yamamoto [2] based on reared associated material. The genus was stated to show close relationship to some Lauterborniella related genera, such as Apedilum Townes, Zavreliella Kieffer and Paralauterborniella Lenz which are characterised in the larva by having a six-segmented antenna and alternate Lauterborn organs (Microtendipes group sensu Cranston et al. [3]), although the adult male of Yaeprimus lacks the median volsella or enlarged superior volsella base characteristic of the group.

Simultaneously, Harrison [4] described four new Chironomidae genera from South Africa, amongst which males of Lunditendipes Harrison shared similar fore tibia and anal tergite setae with the Asian Yaeprimus. Noticeably, an important diagnostic character that appears to distinguish Lunditendipes from Yaeprimus is the absence of basal setae of the superior volsella according to Harrison's original description. However, this is a flawed observation according to the examination of the types materials deposited in ABM by Helen Barber-James. Actually, those specimens bear two inner basal setae clearly arising from tubercle-like setigers and two heavily sclerotized concavities each containing two strong setae in tergite IX, thus resembling Y. isigaabeus [5]. The same character states have been observed also on material deposited in ZSM, which were collected from Kruger National Park in north-eastern South Africa and identified as Lunditendipes by Martin Spies [6]. The two species of Y. isigaabeus and 
L. tropicus show considerable similarity justifying our assessment that they are congeneric, despite differences in the anal tergite band and the shape of gonostylus.

During a survey of rural areas in Guangzhou, a distinct male adult was reared from stream sediment, which conformed largely to the generic diagnosis of Yaeprimus but its color pattern on the abdomen and legs clearly differs from that of the type species $Y$. isigaabeus. Subsequently, similar specimens collected by the NKU Chironomidae group in Hainan were allocated into the above unknown species after a thorough comparison [7]. Here we confirmed it as new to science and described it based on adult males and pupae.

The systematic position of Yaeprimus has received little attention since Yamamoto and Yamamoto's morphological revision [8] which remains somewhat uncertain, and therefore a more integrated taxonomic work is needed to detect the placement of Yaeprimus within tribe Chironomini. Here, we conducted a phylogenetic inference based on five genetic loci (18S, 28S, CAD1, CAD4, and COI-3P) to test the Yamamoto's hypothesis and to explore the boundary of the Microtendipes group. Additionally, some possible placement and dubious features are discussed.

\section{Materials and Methods}

\subsection{Morphology}

Fieldwork was conducted using several classical methods for chironomids collection [9-11]. Adults were caught by light trap and sweeping nets along the aquatic sites. Pupal exuviae were sampled using dip nets (mesh size $250 \mu \mathrm{m}$ ). All samples were preserved in the field with $85 \%$ ethanol, then transferred to the laboratory for sorting under a stereomicroscope. Thorax of adults were sampled for DNA extraction, after that, each cleared exoskeleton was mounted permanently in Euparal on microscopic slides with corresponding parts following standard procedures [12]. Identifications were made under a compound microscope with reference to a range of identification tools and published papers $[1,2,13,14]$. Morphological terminology and abbreviations mainly followed Sæther [15] except the superior volsella. Here the superior volsella base and superior volsella digitus proposed by Cranston [16] are adopted. Measurements were taken according to Epler [17] and given as ranges and followed by average value. The number of observed specimens was recorded in parentheses if it differed from the number (n) stated at the beginning of the description.

\subsection{Molecular Work}

DNA was extracted using MAGEN ${ }^{\circledR}$ (Beijing, China)Tissue DNA kit in the Molecular Lab of Institute of Groundwater and Earth Science, Jinan University, and QIAGEN ${ }^{\circledR}$ (Hilden, Germany) DNA Blood and Tissue kits at the Tianjin Agricultural University. Standard protocols were followed except for the lysis time and final elution volumes, and all the samples were lysed overnight at $55^{\circ} \mathrm{C}$ and eluted with $40 \mu \mathrm{L}$ of eluent. Universal primers were adopted following previous studies (Table A1). Processes for gene fragments amplification were followed as previous studies except for slight moderation of annealing temperature [18-20]. Polymerase chain reaction (PCR) products were electrophoresed in $1.0 \%$ agarose gel, then shipped to Majorbio Company, Guangzhou for purification and bidirectional sequence. One mitochondrial gene (COI-3P), two ribosomal genes (18S and 28S), and two sections of the nuclear protein-coding gene (CAD1 and CAD4) were chosen as in Cranston's work to match the comprehensive dataset of Chironomidae. Additionally, the standard barcode, one fragment of the mitochondrial gene (COI-5P) proposed by Hebert [21] was sequenced to explore cryptic species and calculate generic distance.

Forward and reverse sequences were assembled automatically and manually edited with Sequencher 4.8 (Gene Codes Corp.). Alignment of the sequences used Muscle algorithm [22] on nucleotides in MEGA X [23]. Some ambiguous bases were eliminated based on the results of alignments and trace file, while the remnants were adopted and showed in the International Union of Pure and Applied Chemistry (IUPAC) code. For protein-coding genes, introns were excised using the GT-AG 
rule [24] and an amino acid alignment was used as a guide to elucidate exon/intron boundaries. For $18 \mathrm{~S}$ and $28 \mathrm{~S}$ rDNA, ambiguous regions were excluded with GBlocks v0.91b using default setting except allowing half gap positions within the final blocks $[25,26]$. All selected genes except for the standard barcode (COI-5P) were concatenated with PhyloSuite v1.1.14 [27] to implement the maximum likelihood and Bayesian inference. In case of missing gaps, they were filled up by "?" to ensure that all sequences were in the same length. The optimal models for each subset were selected by Partition Finder 2 [28] based on the Bayesian information criterion (BIC) and corrected Akaike information criterion (AICc). The best scheme was as follows: GTR $+\mathrm{I}+\mathrm{G}$ for the $18 \mathrm{~s}, 28 \mathrm{~s}$ and the first two codons for all protein-coding sequence, $\mathrm{GTR}+\mathrm{G}$ for the third codon of $\mathrm{COI}-3 \mathrm{P}$ and $\mathrm{GTR}+\mathrm{I}+\mathrm{G}$ for third codon of CAD1 and CAD4. Maximum likelihood (ML) phylogenetic analysis was conducted using IQ-TREE 1.6.8 [29] with 1000 bootstrap replicates in a rapid bootstrap analysis and a "greedy search" for the best-scoring ML tree. Bayesian inference was performed in MrBayes v3.2.6 [30]. During the processes, Markov chain Monte Carlo (MCMC) iterations were run with four chains on two runs for 10 million generations, sampled every 100 generations with a burn-in of 0.25 . Convergence among the runs was monitored using Tracer v1.6 [31], with the first 25\% trees discarded as burn-in. The final average standard deviation of split frequencies was 0.003 . Both analyses were completed using the best fitting scheme selected by Partitionfinder. Two species of tribe Tanytarsini were selected as outgroups for this has been considered to be the nearest neighbor of the tribe Chironomini.

In total, 235 sequences of 51 specimens were added to the molecular dataset, 112 of which were downloaded from GenBank (https://www.ncbi.nlm.nih.gov/genbank/) and five of which retrieved from BOLD (Table A2). Forty species were chosen to stand for four complexes, two groups and some ambiguous genera within Chronomini referring to a previous study [3]. Members of Microtendipes were enlarged particularly to test the Yamamoto hypothesis. Specimens with less than three markers were excluded from the dataset of concatenated genes. List of all species, specimens, individual images, georeferences, primers, sequences, trace files and other relevant laboratory data of sequenced specimens can be seen online through the publicly accessible dataset "Yaeprimus" on the BOLD website (www.boldsystems.org) [32,33].

\subsection{Mapping}

The distribution map (Figure 1) was made using ArcGis ${ }^{\mathrm{TM}}$ software [34], with all possible GPS locations of 17 sites implanted into the vector of World Map (http://www.vectorworldmap. com). For older specimens without GPS data, estimates were made from the finest available detail (e.g., city/country) available from either specimens or publications. 


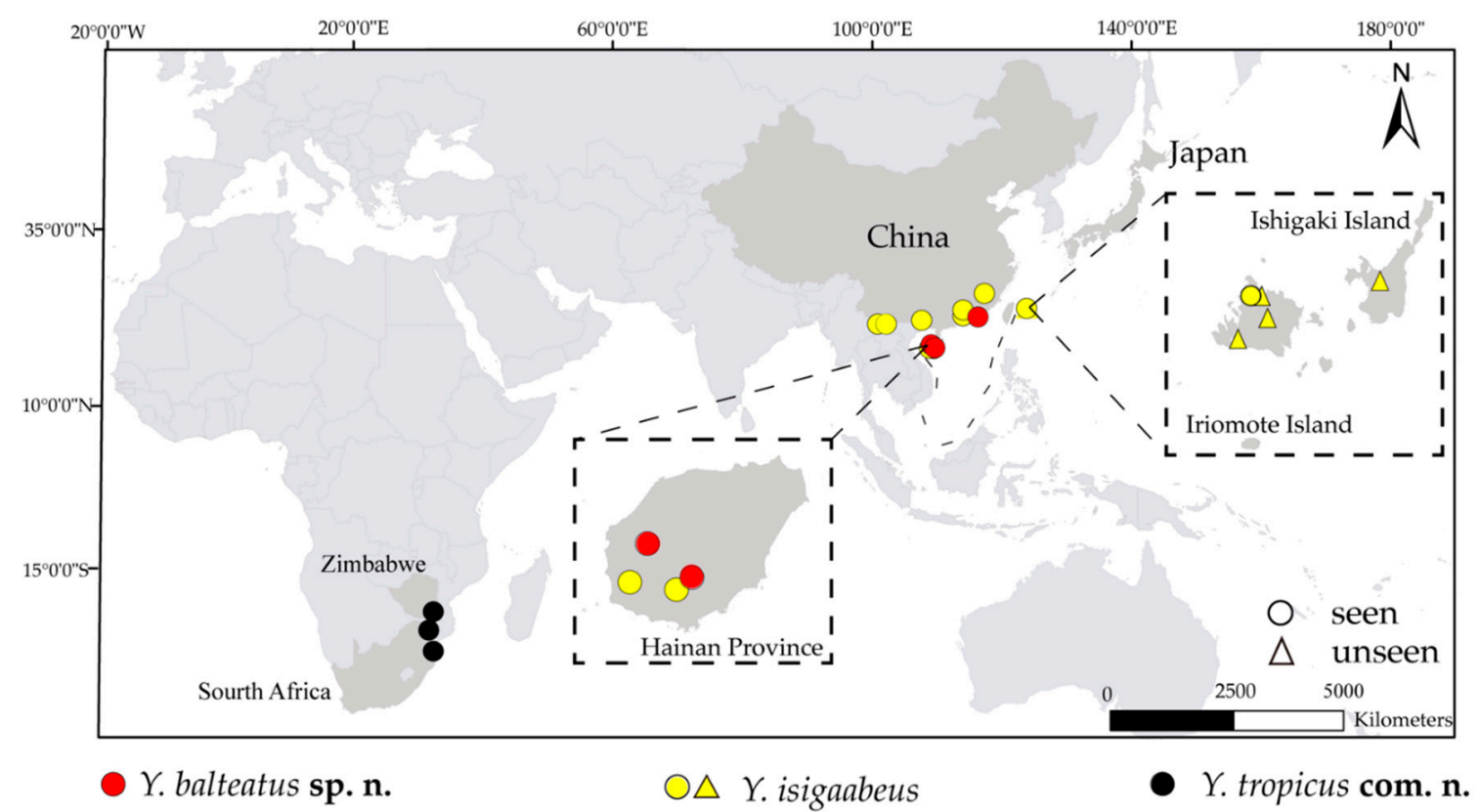

Figure 1. Distribution map of Yaeprimus.

\subsection{Abrreviation}

Institution: ABM, Albany Museum, South Africa; EJNU, Institute of Groundwater and Earth Science, Jinan University, China; NKU, College of Life, Nankai Universtiy, China; ZSM, Zoologische Staatssammlung Muenchen, Germany.

Terminology: Life stage, F, female; L, larva; M, male; P, pupa. Morphology, T II-X, tergite II to X; $\mathrm{Ta}_{1}-\mathrm{Ta}_{5}$, tarsus 1 to tarsus 5. Molecular, BS, bootstrap support; PP, posterior possibility.

\section{Results}

\subsection{Molecular Analysis}

\subsubsection{DNA Barcode}

Three COI DNA barcodes of new species from adult males clustered into the same BIN (BOLD:ADH0469), with a maximum intraspecific pairwise genetic distance of $0.64 \%$, and $11.38 \%$ divergence to the nearest BIN (BOLD:ACT7861). The nearest neighbor (Sample ID: BIOUG28352-C08) from Guanacaste in Costa Rica, was unidentified in BOLD.

\subsubsection{Phylogenetic Analysis}

The structure of the maximum likelihood (ML) tree was basically similar with that of the Bayesian inference (BI) tree except for some weakly supported clades. As expected, both approaches strongly supported (node $\mathrm{A}, \mathrm{BS}=100, \mathrm{PP}=1$ ) that $Y$. isigaabeus and new species group together. Yaeprimus together with Imparipecten Freeman forms a new clade in both trees (node B, BS $=82$, PP $=0.98$ ), then the clade is sister to the assemblage of Chironomus complex, Harnischia complex and Nilothauma Kieffer (node C) in ML tree, while shifts to the assemblage of Polypedilum Kieffer, Endochironomus Kieffer and Stenochironomus Kieffer (node C) in BI tree, but either connections to Chironomus or Polypedilum clades without support. The positions of remaining genera mostly conform to previous results [3]. Besides Yaeprimus, something interesting has been discovered in our study. After the inclusion of Chinese populations, Nilothauma is verified as sister to the Chironomus complex + Hanischia complex (node D, $\mathrm{BS}=83, \mathrm{PP}=0.99)$, which showed some tendency in previous work [3] but without robust support. In a Microtendipes group (Node E, BS $=90, \mathrm{PP}=0.99$ ), the Chinese populations of Paratendipes (node G) are paraphyletic although lack of support. Saether's hypothesis [35], based on characters of female 
adults that Patatendipes is sister to Microtendipes + Nilothauma, is rejected in both analyses. Our results show that Patatendipes (node F, BS $=100, \mathrm{PP}=1$ ) is close to Paralauterborniella Lenz, while Microtendipes is close to Australian Paucispinigera Freeman (Node H, BS =99). The positions of Apedilum Townes (node I) and Paraborniella Freeman (node J) vary within acceptable range between two analyses, tough both nodes are weakly supported (Figures 2 and 3).

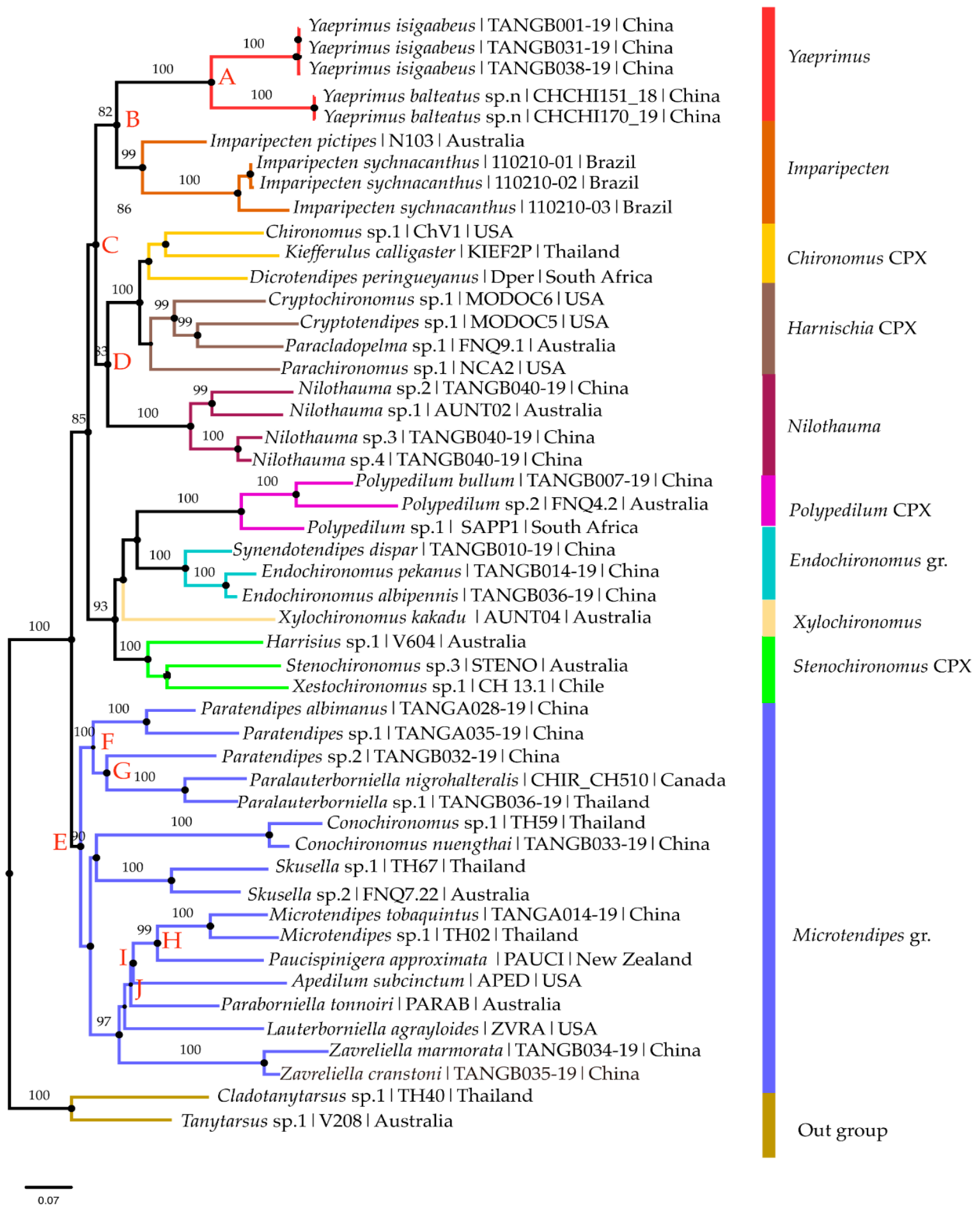

Figure 2. Maximum likelihood tree based on concatenated gene (18S, 28S CAD1, CAD4, COI-3P) fragments. Nodes are labeled by bootstrap support (BS), only BS $>0.8$ are shown. 


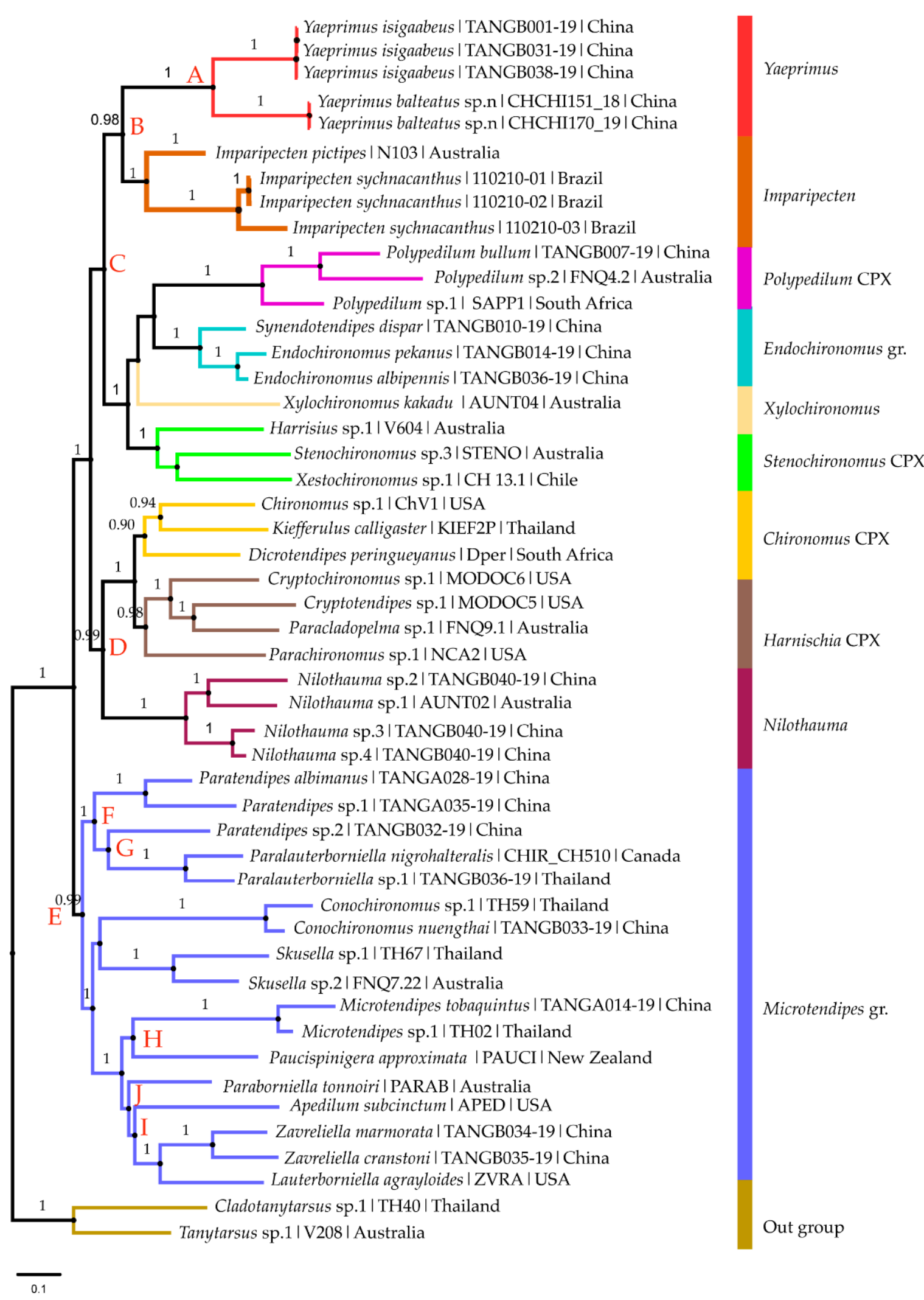

Figure 3. Bayesian inference tree based on concatenated genes (18S, 28S CAD1, CAD4, COI-3P) fragments. Nodes are labeled by posterior possibilities (PP), only PP $>0.90$ are shown. 


\subsection{Morphology}

\subsubsection{Generic Diagnosis Emendation}

\section{Yaeprimus Sasa et Suzuki}

Yaeprimus Sasa et Suzuki, 2000 (M).

Yaetertius Sasa et Suzuki, 2000 (M), Yamamoto and Yamamoto, 2000.

Lunditendipes Harrison, 2000: 224 (M), syn. n., type species: Lunditendipes tropicum Harrison by original designation.

Yaeprimus Sasa et Suzuki; Yamamoto and Yamamoto, 2000 (M, F, P, L).

Type species: Yaeprimus isigaabeus Sasa and Suzuki, 2000: 4, by original designation. Other included species: Yaeprimus tropicus (Harrison, 2000), comb. n.; Yaerpimus balteatus sp. $\mathbf{n}$.

Three species conformed to most generic diagnosis given by Yamamoto and Yamamoto [2], except for the following emendations.

Male

Head. Frontal tubules small, hemispheric.

Thorax (Figure 4D, Figure 8A). With a distinct scutal tubercle (Y. balteatus sp. n.) or flat hump (median protuberance) (Y. isigaabeus, Y. tropicus comb. $\mathbf{n}$.), if the latter, smoothly curved in the middle. Humeral pits present.

Legs (Figure 4F, Figure 8B,C). Tibial combs of mid and hind tibiae nearly or completely fused; if separated narrowly (Y. balteatus, Y. tropicus), the large (inner) comb usually bears $0-2$ straight spurs, the small (outer) comb always has a long apically hooked spur. If fused (Y. isigaabeus), there is only one hooked spur, arising more proximally on the outer surface of the comb base. The number of spurs per tibia variable even within a single specimen. Pulvilli present.

Abdomen (Figure 5A). Anterolateral areas of first segment slightly sclerotized with two distinct patches bearing several concentrated setae; T II-VIII with two rows of regular transverse setae centrally. Tergite VIII slightly tapered anteriorly (Figure 4G).

Hypopygium. Tergite IX with a regular row of median anal seta, usually grouped laterally, arising from the distinct pigmented oval field (Figure $4 \mathrm{H}$ ) or blank oval pits (Figure 8F). Anal tergite band absent or weak. Superior volsella (Figure $6 \mathrm{C}, \mathrm{D}$, Figure $8 \mathrm{~F}$ ) with bare base, $1-3$ basal setae, arising from the distinct tubercle base, digitus slender distally or with a slightly elongated ventro-lateral ledge distally (hooked), covering a partial or the whole width of digital apex, lacking any outer seta on digitus. Gonostylus was normal (Figure $4 \mathrm{H}$ ) or reduced (Figure $8 \mathrm{~F}$ ), with several distal-medial setae of different sizes, the seta on the distal-inner corner being the longest and thickest.

Pupa

Tergite spinulation of III-V split into anterior and posterior patches or completely fused. All spinules were nearly uniform sized. Conjunctival bands present on T III and T IV, continuous or medially interrupted. Posterolateral corner of T VIII with 'comb' of 1 main tooth and 3-4 small side teeth. Taeniae pattern (Figure 7A) on A IV-VIII, 4, 4, 4, 4, 4. Uniserial fringe with 20-30 taeniae. Dorsal seta of anal lobe present.

Distribution. Yaeprimus was known only from two small Japanese islands for Y. isigaabeus. Our study has expanded the genus distribution to south China, South Africa, and Zimbabwe. All specimens have been collected from subtropical and tropical regions.

Remarks. The integrated systematical work of Yaeprimus has not been conducted completely before this study. The previous suggested phylogenetic placement was based solely on selected distinctive morphological character states of three life stages, rather than through a formal data matrix. Previously-argued conclusions were not fully reliable lacking rigorous parsimony analysis. Some important characters were ignored, for example, the anteriorly tapered tergite VIII, the inner setal arrangement of gonocoxite, the condition of humeral pit, and the abdominal setae and the pulvilli status. The current inclusion of an additional two species expands the variation within the genus, 
complicating the generic diagnosis. The main morphological differences among the three species are summarized in Table 1.

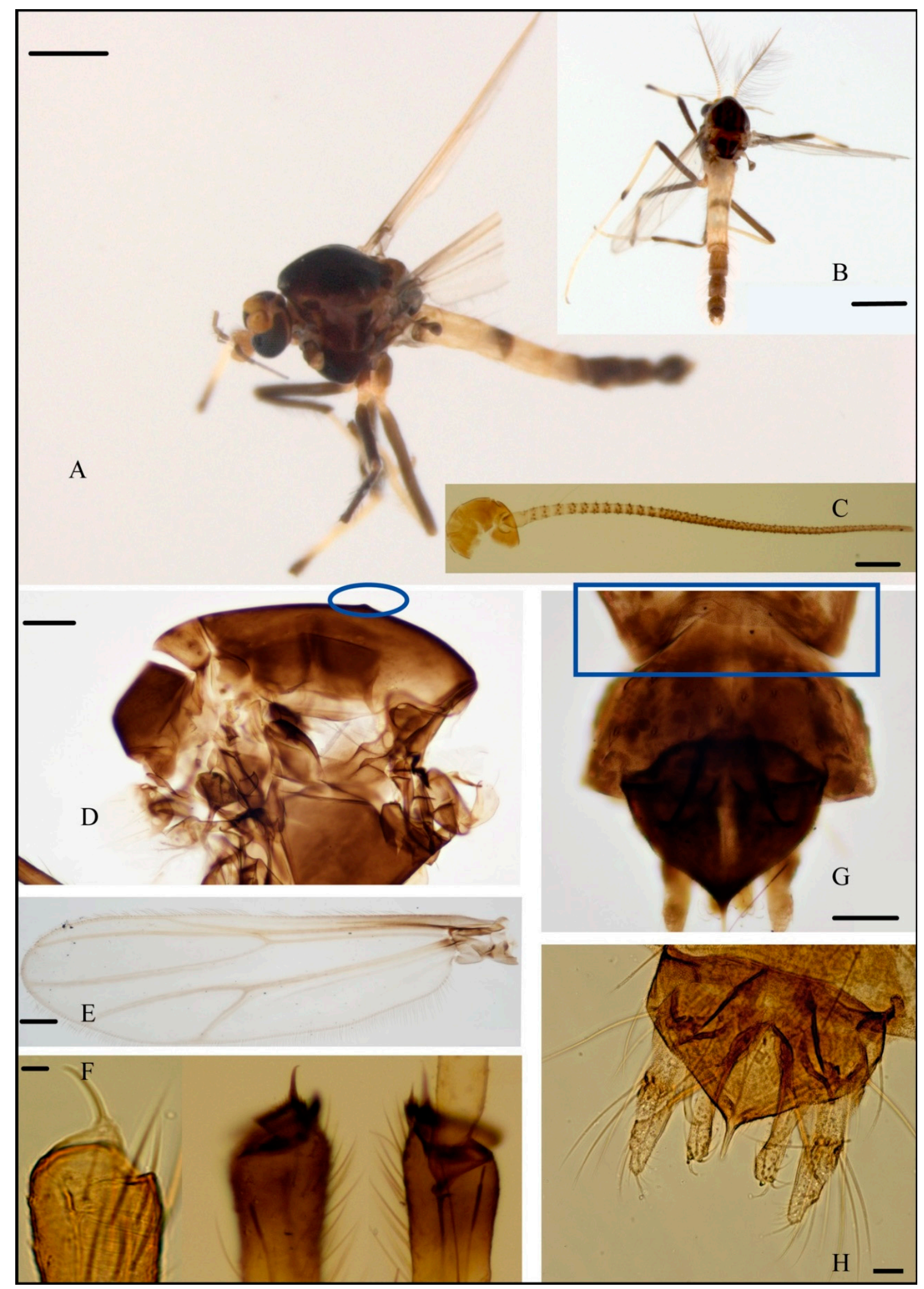

Figure 4. Yaeprimus balteatus sp. n., male. Photos: (A) lateral view; (B) dorsal view; (C) antenna; (D) thorax; (E) wing; (F) tibia; (G) T VIII; (H) hypopygium. Scale bar: A, B, $500 \mu \mathrm{m}$; D-H, $100 \mu \mathrm{m}$. 


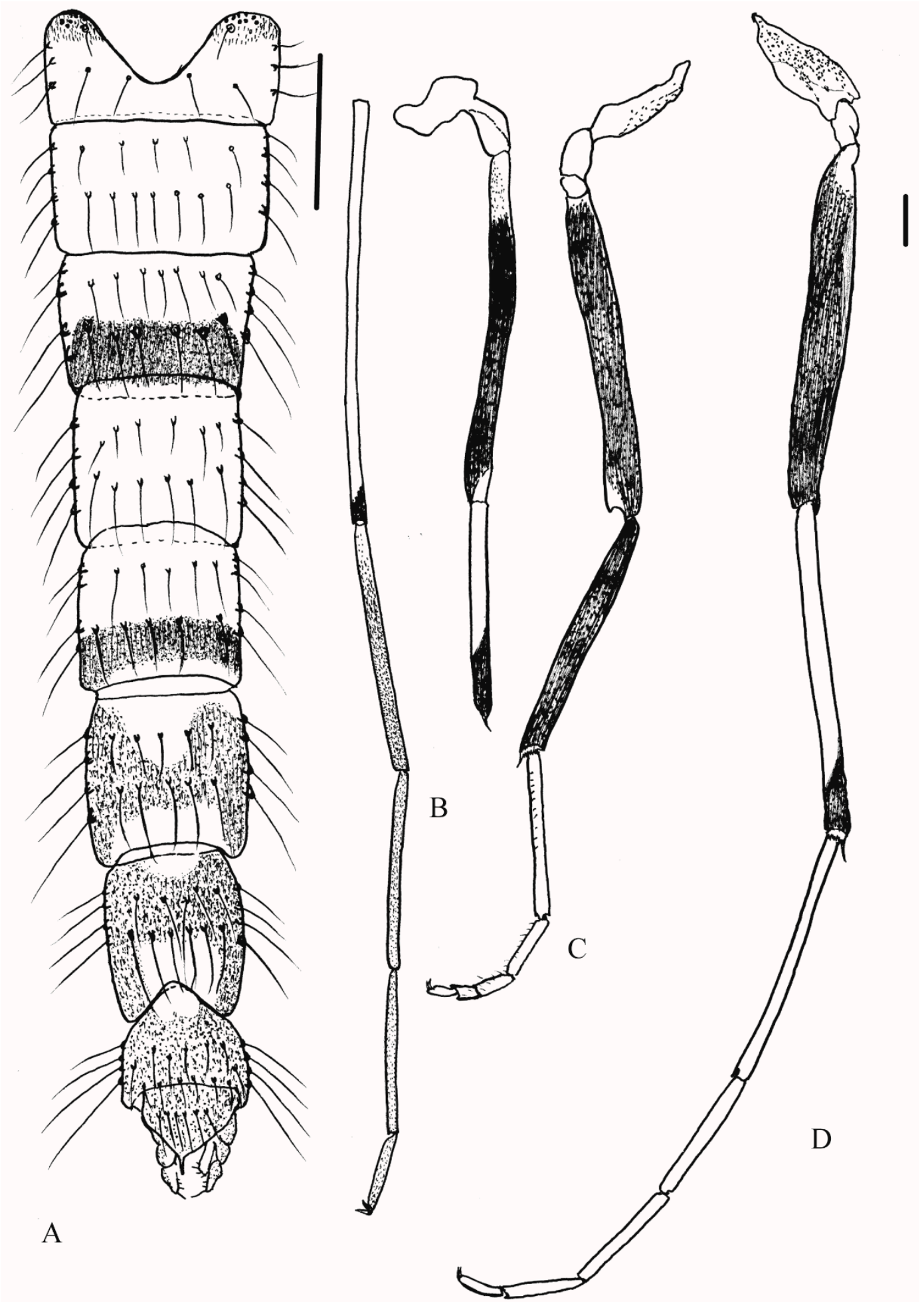

Figure 5. Y. balteatus sp. n., male. Illustration. (A) abdomen; (B) fore legs; (C) mid legs; (D) hind legs. Scale bar: A, $250 \mu \mathrm{m}$; B-D, $100 \mu \mathrm{m}$. 


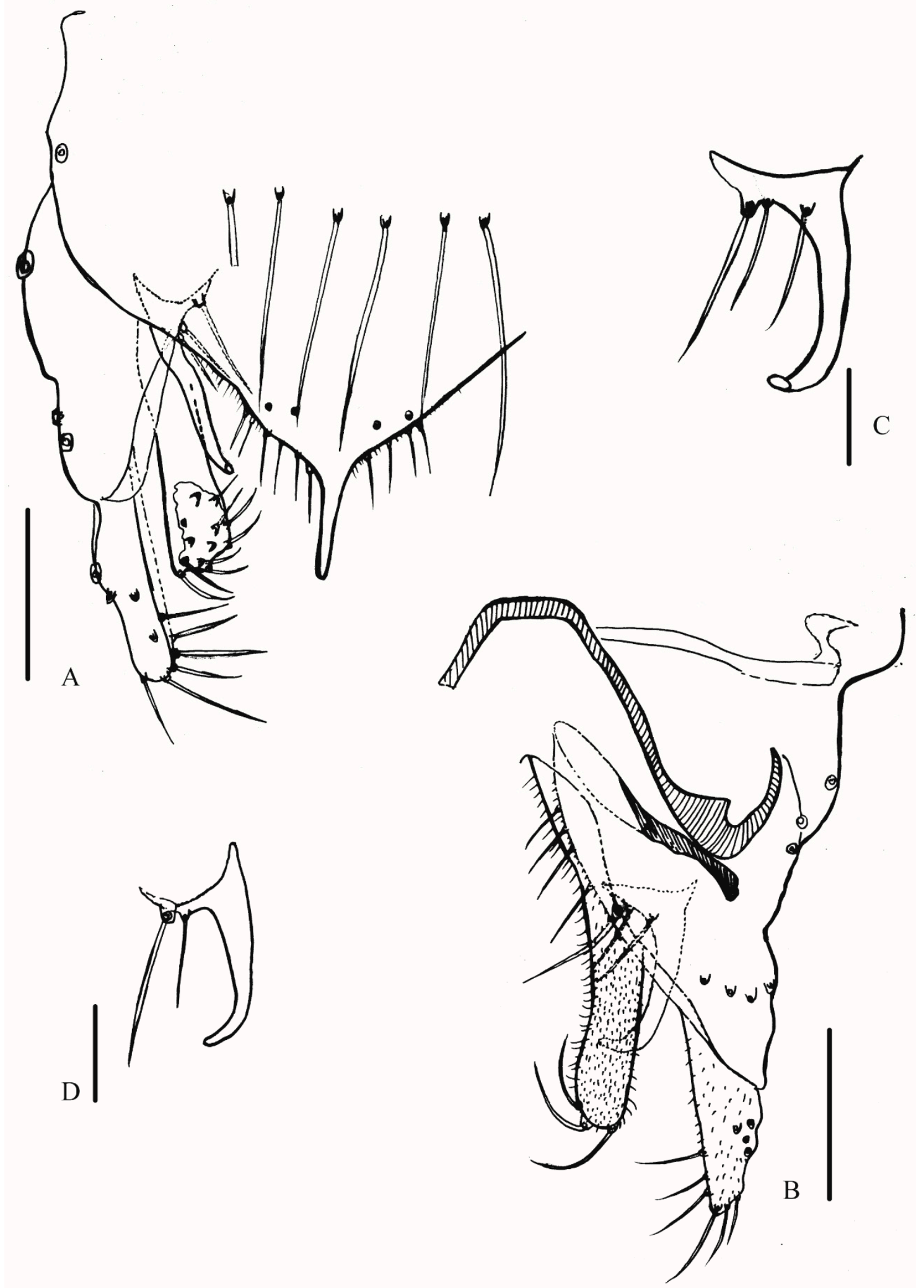

Figure 6. Y. balteatus sp. n., male. Illustration: (A) hypopygium, dorsal view; (B) hypopygium, ventral view; (C,D) superior volsella. Scale bar: A-D, $100 \mu \mathrm{m}$. 


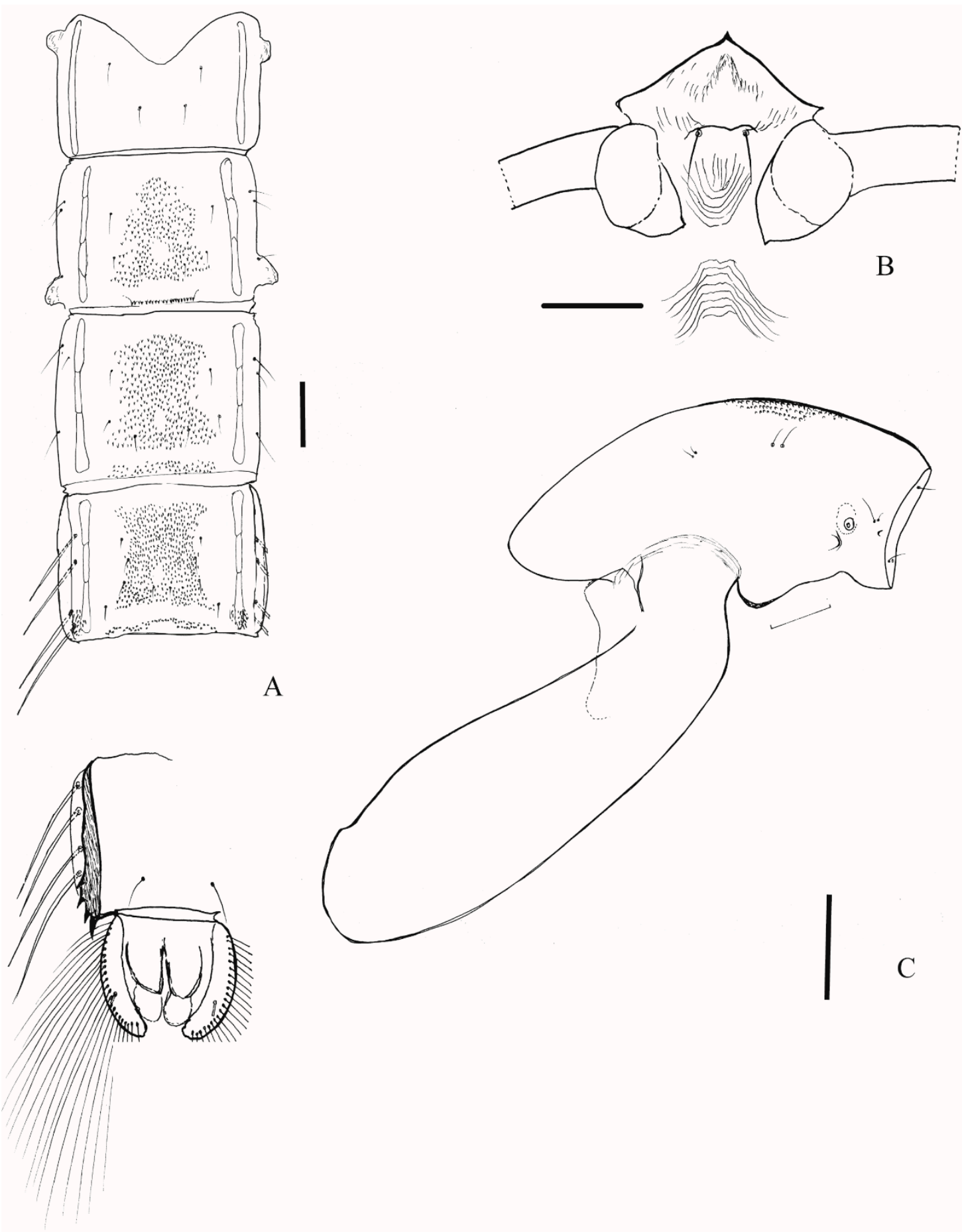

Figure 7. Y. balteatus sp. n., pupa. Illustration: (A) abdomen, dorsal view; (B) cephalothorax; (C) thorax, lateral view. Scale bar: A-C, $100 \mu \mathrm{m}$. 
Table 1. The main morphological differences on male adults of three Yaeprimus species.

\begin{tabular}{cccc}
\hline Features of male & Y. balteatus sp. $\mathbf{n}$. & Y. isigaabeus & Y. tropicus com. $\mathbf{n}$. \\
\hline Scutum & hump, with tubercle & hump, without tubercle & normal, without tubercle \\
Tibial comb & separated & fused & separated \\
Anal tergite band & absent & absent & reduced \\
Anal median setae & 5-6 setae, one row & two pairs, grouped & two pairs, grouped \\
TIX oval concavity & absent & present & present \\
Gonostylus & reduced & reduced & normal \\
\hline
\end{tabular}

\subsubsection{Description of Species}

Yaeprimus balteatus Han et Tang, sp. $\mathbf{n}$.

Material examined (all collected H.Q. Tang, deposited EJNU, unless stated otherwise). Holytype [EJNU-Ershan150910001], male, CHINA: Guangdong Province, Guangzhou City, Ershan county, $23^{\circ} 14^{\prime}$ N, 113 26 $6^{\prime}$ E, 10.ix.2015, light trap; Paratype, 1 male[EJNU-Ershan150320001] and 1 reared pharate female [EJNU-Ershan150521001] as previous, except 20.iii.2015 (emerged 21.v.2015); 1 male [EJNUShantou 151014001], Guangdong Province, Shantou City, Chaonan District, Jinxi Reservoir Scenic spot, Fengzai Village, $23^{\circ} 10^{\prime} \mathrm{N} 116^{\circ} 18^{\prime}$ E, alt. $210 \mathrm{~m}$, 14.x.2016, light trap (ZSM); 1 male[NKU-XL1460], Hainan Province, Changjiang County, Bawangling National Nature Reserve, $19^{\circ} 07^{\prime} \mathrm{N}, 109^{\circ} 05^{\prime} \mathrm{E}$, 13.iii.2016, light trap, B.J. Sun (NKU); 2 males[NKU-XL1509, NKU-XL1510], Hainan Province, Shuiman County, Wuzhi Mountain., $18^{\circ} 45^{\prime} \mathrm{N}, 109^{\circ} 36^{\prime}$ E, sweep net, 2.iii.2016, C. Song (NKU).

Etymology. The new name 'balteatus', derived from Latin (meaning belted), referring to the color bands on the abdomen and leg.

Male $(n=5-6)$ (Figures 4-6)

Total length, 2.50-2.95, 2.70 (5) $\mathrm{mm}$. Wing length, 1.30-1.60, 1.45 (5) $\mathrm{mm}$.

Coloration (Figure 4A,B and Figure 5A). Generally brown with some pattern in legs and abdomen. Legs were yellow, except for dark brown all femur and complete mid tibia, and pale brown apex of fore and hind tibia. Fore-tarsus with brown apex and gradually brown in $\mathrm{Ta}_{2}-\mathrm{Ta}_{5}$, others tarsi all pale yellow (Figure 4A,B for colorful photo). Anterolateral corners of A I, posterior half of A III and A V, and almost entire A VI-VIII dark brown. A IX was dark brown, the hypopygium with brown gonocoxite and pale yellow gonostylus.

Head. Antenna (Figure 4C) with pale brown (approximal and distal) or brown (middle) flagellomeres, with almost dark plume. Flagellomere 1-12, 340-390, 358; flagellomere 13, 540-640, 570; AR 1.57-1.64, 1.60 (4). Palpomere lengths (in $\mu \mathrm{m}$ ): 25-30, 28 (3); 25-35, 30 (3); 115-125, 120, (3); 100-124, 111 (3); 180-200, 190. Temporals were 10-12, 11. Clypeus had 14-17, 15 (5) setae. The diameter of cephalic tubercle $5 \mu \mathrm{m}$, bearing 3-5 small setae.

Thorax (Figure 4D). Antepronotals 1-2; dorsocentrals 6-9, 6, usually alternately accessorized with 3-5 tiny pits; acrostichals 10-16, 14 (3) arranged in robust two rows, ending in anterior $1 / 3$ before the hump; prealars $3-4,3$, supraalars 1 . Scutellum had 7-8 setae, in single row. Tiny trans-oval humeral pits present.

Wing (Figure 4E). VR 1.09-1.22, 1.16 (5); $R$ without seta; $R_{1}$ with $0-1$ seta; $R_{4+5}$ with $1-2$ setae in extreme apex. Squama bare.

Legs (Figures 4F and 5B-D). Fore tibia with a conical scale bearing a slender, distal-hooked spur, 25-30 (2) $\mu \mathrm{m}$ long. Mid tibia with two separated combs, one bearing a distal-hooked spur, 23-37, 28 (3) $\mu \mathrm{m}$ long, another comb with even comb teeth, unspurred; hind tibia with two separated combs, the small one bearing a distal-hooked spur, 25-40, $35 \mu \mathrm{m}$ (5) long, and the large one bearing 1-2 straight spurs, 12.5-20, 16.5 (5) long. $\mathrm{LR}_{1} 1.30-2.19$ (2); $\mathrm{LR}_{2}$ 0.58-0.71, 0.65 (3); $\mathrm{LR}_{3} 0.77-0.83,0.80$ (3). $\mathrm{BV}_{1}$ 1.44-2.28(2); $\mathrm{BV}_{2}$ 5.31-5.88, 5.54(3); $\mathrm{BV}_{3}$ 2.44-2.61; 2.54 (3). $\mathrm{SV}_{1} 1.30-2.12(2) ; \mathrm{SV}_{2} 3.20-4.06,3.54$ (3); $\mathrm{SV}_{3}$ 2.59-2.70, 2.63(3). $\mathrm{BR}_{1} 2.25-2.50(2) ; \mathrm{BR}_{2} 3.57-4.00,3.78$ (3); $\mathrm{BR}_{3} 3.2-5.36,4.25(3)$. 
Hypopygium (Figures $4 \mathrm{H}$ and $6 \mathrm{~A}, \mathrm{~B})$. T IX with a row of 4-6 setae, arising from fairly large microtrichia-free pit, without distinct lateral group. Distal margin with 3-5 setae both in the dorsal and ventral surfaces. Gonocoxite 115-132, 126 (4) $\mu \mathrm{m}$ long. Gonostylus relatively short, 35-48, 43 (4) $\mu \mathrm{m}$ long, distal portion with 6-10 inner-toward setae, the longest one about 25 long. Superior volsella (Figure 6C,D) with a base without microtrichia, bearing 2-3 inner setae from the tubercle base, distal digitus long and slender, distal curved inwardly, without inner seta. Inferior volsella slightly bullous distally, with 13-16 setae. HR 2.79-3.29, 2.97 (4); HV 5.58-7.14, 6.37 (4).

Pupa $(n=1)$ (Figure 7$)$

Total length ca. $3.0 \mathrm{~mm}$. Cephalic tubercle absent (Figure 7B), frontal setae small, $40 \mu \mathrm{m}$ long, subequal to the gap between two frontal setae. The thoracic setation as in Figure $7 \mathrm{C}$, thoracic horn invisible. The abdomen (Figure 7A) with dense spinulations in T II-IV, no clear delimitation between the anterior patch and median patch. Continuous conjunctival spinule bands present in T III and IV. The tergite II hook row continuous, short, $30 \%$ of the width of segment II, comprising ca. 20 hooks. A V-VII distorted. Comb VIII with one main tooth and three small accessory teeth. The anal lobe $140 \mu \mathrm{m}$ long and $150 \mu \mathrm{m}$ wide, with 20-24 taeniae, dorsal seta present.

Remarks. The new species shares the same comb pattern with $Y$. tropicus and reduced gonostylus with $Y$. isigaabeus. It can be distinguished from the other two species by the distinct scutal tubercle and anal median tergal seta arising from the common pale pit rather than sclerotized concavities. For pupa, the new species can be separated from Y. isigaabeus by the fused sub-rectangular spinulations and small point-free area in the middle area of T II-IV and conjunctives continuously.

Distribution: China (Guangdong and Hainan).

Yaeprimus isigaabeus Sasa et Suzuki

Yaeprimus isigaabeus, Sasa and Suzuki, 2000: 4; Yamamoto and Yamamoto, 2011: 228.

Yaetertius iriojekeus Sasa et Suzuki, 2000: 18, synonymized by Yamamoto and Yamamoto, 2011.

Material examined (all collected H.Q. Tang, deposited EJNU unless stated otherwise): 1 male, 1 female, CHINA: Fujian Province., Zhangzhou City, Nanjing County, a stream in Huboliao National Nature Reserve, $26^{\circ} 31^{\prime}$ N 117 $18^{\prime}$ E, 15.xi.2012; 6 males, China: Guangdong Province, Guangzhou City, Zengcheng District, Shuimei County, Lan stream, $23^{\circ} 21^{\prime}$ N, $113^{\circ} 58^{\prime}$ E, alt. 148, 29.xi.2018, light trap; 1 Pe, Guangdong Provinve, Guangzhou City, Conghua District, Xinlian village, $23^{\circ} 47^{\prime} \mathrm{N}, 113^{\circ} 59^{\prime}$ E, alt. 240 m, hand net, 18.x.2014; 1 male, CHINA: Hainan Province, Baoting County, Xian'an Shilin scenic spot, $18^{\circ} 36^{\prime}$ N 109 25’ E, alt. 602 m, 14.ii.2015; 2 Pe, Guangxi Province, Congzuo City, Detian waterfall, $22^{\circ} 51^{\prime} \mathrm{N}, 106^{\circ} 44^{\prime}$ E, alt. $380 \mathrm{~m}$, 24.ii.2012, W. Xia and C.B. Duan; 1 male, CHINA: Yunnan Province, Xishuangbanna Prefecture, Jinghong City, Mengyang County, Xishuangbanna Prefecture, Wild Elephant Valley, $22^{\circ} 10^{\prime} \mathrm{N}, 100^{\circ} 51^{\prime}$ E, $900 \mathrm{~m}$ asl., sweep net; 1Pe, Yunnan Province, Xishuangbanna Prefecture, Jinghong City, Menglun Town, Luosuo River, $21^{\circ} 55^{\prime}$ N $101^{\circ} 17^{\prime}$ E, 22.iii.2019.

Additional compared specimens: 2 males, JAPAN: 2 males, Iriomote Island, Funaura, one slide 24. iii. 2000, another 19.xi.2001, M. Yamamoto.

Conforms mostly to Yamamoto and Yamamoto [2], with the following supplementation and emendation:

Male

Total length 1.8-3.2 mm, wing length 1.1-1.8 mm. AR 1.15-1.50. $\mathrm{LR}_{1}$ 1.57-2.36. Distinct humeral pit present.

Anal tergite with two pairs or three pairs of median setae, arising from a heavily pigmented field, grouped laterally. Superior volsella base with 1-2 inner seta, without microtrichia, digitus with a basal inner seta, and distal elongated, with a ventro-lateral ledge apically.

Pupa

Cephalic tubercle absent, frontal setae reduced, subequal to the gap between two setae. Dorsal seta of anal lobe present. 
Distribution. Japan (Ishigaki Island and Iriomote Island); China (Fujian, Guangdong, Hainan, Guangxi, Yunnan).

Yaeprimus tropicus comb. $\mathbf{n}$.

Lunditendipes tropicum Harrison 2000: 224

Material examined (all observed by Helen Barber-James, confirmed with authors by the shared photos).

Holotype (CCA. 40G). M, Zimbabwe: Lower of Lundi River, $21^{\circ} 20^{\prime}$ S $32^{\circ} 15^{\prime}$ E, 25.iv.1962, A.D. Harrison; two paratype (GEN. 265AL; GEN. 268AL), Zimbabwe: Ndumu Game Rivers, KwaZulu-Natal, $26^{\circ} 53^{\prime}$ S $32^{\circ} 18^{\prime}$ E, 19.xi.1959, A.D. Harrison.

This species has been described by Harrison [4]: some emendations and additional characters are given here.

Male $(n=4)$ (Figure 8)

AR 1.2-1.5, LR 2.1-2.3; thorax (Figure 8A) slight hump, without scutal tubercle, small pale humeral pit present. Mid (Figure 8B) and hind tibia (Figure 8C) with two separated combs, the small combs with long-hooked spurs, the large comb without spur in the mid tibia, with 1-2 outstanding straight spurs in the hind tibia. Pulvilli present. Abdomen II-VIII with two regular rows of setae, T VII (Figure 8D-F) slightly tapered anteriorly. Location of anal tergite median setae (Figure $8 \mathrm{D}-\mathrm{G}$ ) as that in $Y$. isigaabeus, two pairs of strong setae arising from the heavily pigmented areas, with variation one side two setae, another side three. Apart from those two pigmented areas, an isolated additional seta may present, arising directly from the cuticle. Superior volsella basal (Figure $8 \mathrm{H}$ ) with two inner basal setae arising from tubercles, digitus bare, with a weak ventro-lateral ledge apically. Gonostylus is not reduced, normal (Figure 8D-G).

Remarks. Y. tropicus was characteristic by having a normal gonostylus and a weak tergal band. Distribution. Zimbabwe (Lundi River); South Africa (KwaZulu-Natal). 

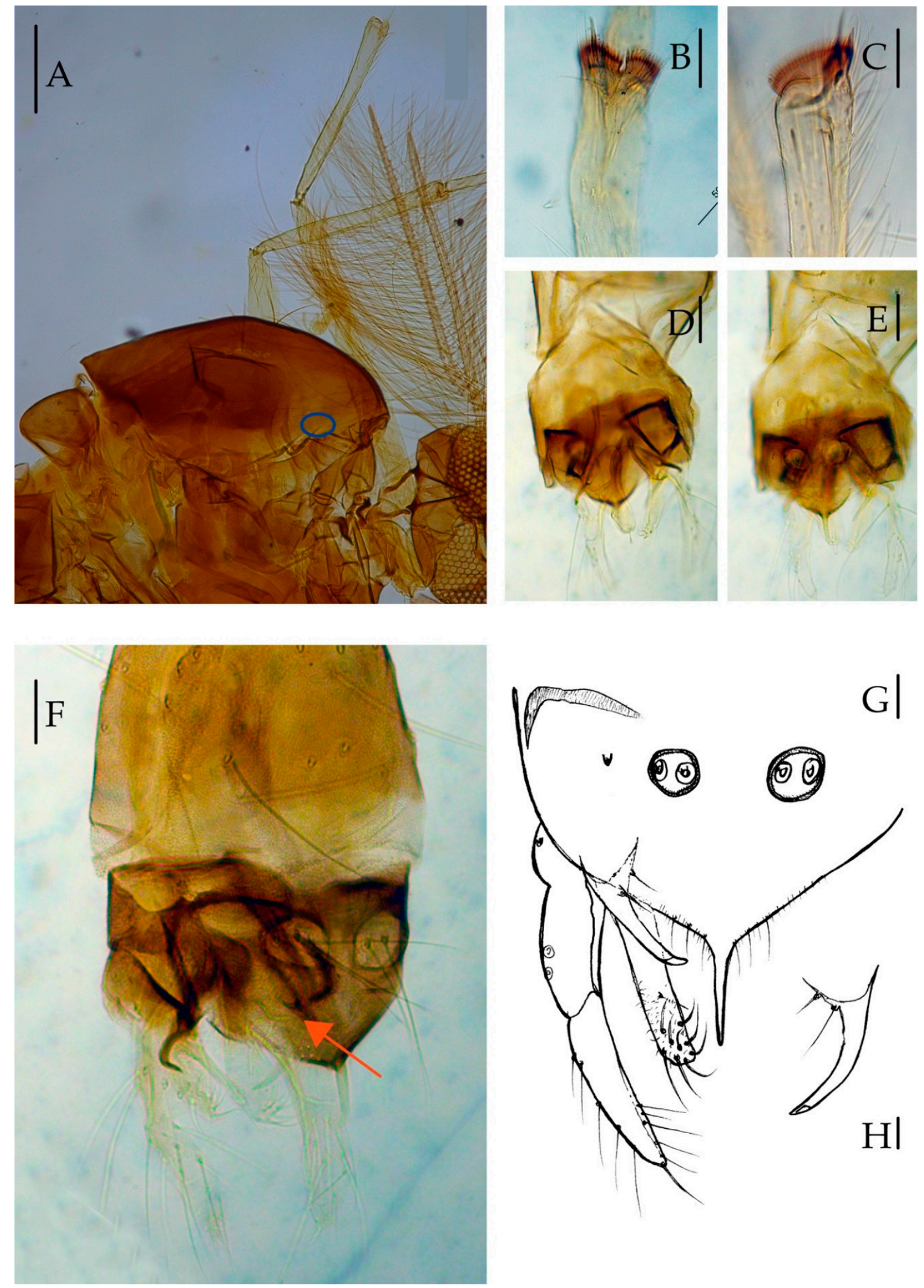

Figure 8. Yaeprimus tropicus comb. n., male. (A) Thorax, head, lateral view; (B) mid tibia; (C) hind tibia; (D) hypopygium, ventral view; (E), hypopygium, dorsal view; (G), hypopygium, illustration, dorsal view; (H) superior volsella. Scale bar: A, $200 \mu \mathrm{m}$; B-F, $100 \mu \mathrm{m}$. A, (F) Holotype (CCA. 40G]); B-C: Paratype (GEN. 268AL); D-E, G: Paratype (GEN. 265AL). 


\section{Discussion}

It is a great challenge to include $Y$. tropicus and $Y$. balteatus into a single genus since the two species show great divergence comparing to species $Y$. isigaabeus, especially in the often-diagnostic tibial comb pattern. Although molecular results well support $(B S=100, P P=1)$ the great affinity between $Y$. balteatus and $Y$. isigaabeus (see red clade), the monophyly of Yaeprimus could not be validated until the availability of molecular data of $Y$. tropicus. Here, the reasons why we allocate the three species into one genera are as follows. Y. isigaabeus and Y. balteatus lack tergite bands and bear a relatively short gonostylus, whereas $Y$. tropicus has a weak tergite band and normal gonostylus. The divergence is distinct yet can be also observed in other genera as well. For example, Pontomyia Edwards also contain two kinds of gonostylus, reduced in P. oceana Tokunaga, while, normal in other two species [36]. More examples can also be found in Chironomus (C. crassiforceps Kieffer) [10], Polypedilum (P. minimus Lin et al.) [37], Riethia (R. phengari Cranston) [16], Sticotochironomus (S. crassiforceps Kieffer) [10] and Orthocladius v. d. Wulp (O. brevistylus Yamamoto, Yamamoto et Tang) [38]. Actually, the shortened gonostylus has been assumed to relate to the convergent mating behavior since a range of species sharing this character has been found in some extremely habitats, such as marine, karst cave and alpine fauna [39]. Variation on tergite IX band from normal to absent can be treated as a continuously varying trait in a single genus because such divergence can also be found in Apedilum [40-42], Paralauterborniella [8] and Beardius [43].

The conical scale bearing a slender apical spur in the fore tibia is an important character state allowing us to allocate the three species into one genus, but the differences in mid and hind tibial combs are noteworthy. The two different patterns of tibial comb in Yaeprimus seem to represent two different evolutional trends. The pattern of fused comb with one curved spur will go to some non-core Microtendipes group such as Nilodosis Kieffer and Kribiocosmus Kieffer. Separated combs with 1-2 hooked spurs are typical in the core members of Microtendipes group and in the Polypedilum complex. Normally, species bearing two different kinds of tibial combs cannot be allocated into one genus, but some special cases can be also found in Parachironomus Lenz [6] and Synendotendipes Grodhaus [44].

The scutal tubercle can also be treated as a synapomorphy. That continual variation can also be found in some tanypods, like Procladius Skuse [45], Coffmania Hazra and Chaudhuri [46], and some orthoclads, such as Parakiefferiella Thienemann [47] and Rheosmittia Brundin [48], and also in Demicryptochironomus Lenz [49].

Our molecular analysis indicates that Yaeprimus is sister to Imparipecten and distant from the Microtendipes group. Yaeprimus shares similar characters with Imparipecten, such as the superior volsella formed as a digitus in male adults, alternate apically-located Lauterborn organ in the larval antenna, and pattern of pupal taeniae of T V-VIII is 4, 4, 4, 4, yet the two genera can be easily separated in all life stages. The conflict between Yamamoto's hypothesis and our molecular analysis is likely a result of some subjective weighting of some morphological characters, such as female genitalia and larval antenna. Actually, some emphasized characters by Yamamoto and Yamamoto are common in a broader range of genera.

In larvae, alternate Lauterborn organs in Yaeprimus share the synapomorphy with most members in the Microtendipes group. But this trend is not constrained to this group, as similar Lauterborn organ pattern can be also found in Polypedilum nubifer group [50], Imparipecten [51] and Sticotochironomus. Yamamoto and Yamamoto [2] misinterpreted that larva bears a five-segmented antenna with two large Lauterborn organs on segment two which led them to regard it as an apomorphic condition.

Pupa of Yaeprimus shows apparent similarity to Paralauterborniella both in tergal spinulation and taeniae pattern. The two genera mainly differ in the condition of cephalic tubercle, which is absent in Yaeprimus while present in Paralauterborniella [9]. In this case, other pupal characters should be evaluated to balance the conflict between molecular analysis and morphology.

Meanwhile, we should notice that the position of clade Yaeprimus plus Imparipecten is unstable in both trees, which may be caused by an insufficient sample. Given the morphological divergence between Imparipecten and Yaeprimus, we hypothesized that there were still some other unknown genera 
showing great affinity with the above clade, linking the two genera and establishing their position within Chironomini.

In conclusion, we redefine genus Yaeprimus based on morphological and molecular evidence. Currently, there are three species included in the emended genus. Our molecular result supports Yaeprimus is close to Imparipecten rather than to the Microtendipes group, but some uncertainty remains due to limitations in sampling. To bridge the gap between morphologic and molecular results, more relevant genera are in demand for further studies.

Author Contributions: Conceptualization, H.T.; methodology, W.H. and X.L.; formal analysis, W.H. and X.L.; data curation, W.H. and J.W.; writing-original draft preparation, W.H.; writing-review and editing, H.T. All authors have read and agreed to the published version of the manuscript.

Funding: This research was supported in part by the NSFC fund (No. 41672346) and the university grant (No. 21617446).

Acknowledgments: Great thanks to Helen Barber-James, Department of Freshwater Invertebrates, Albany Museum, Somerset St Makhanda (Grahamstown), South Africa, a DSRAC-funded museum, for checking the type material of Lunditendipes tropicus Harrison. Special thanks to Martin Spies, Zoologische Staatssammlung München (Munich), for discussing morphological variation of Yaeprimus. We are deeply indebted to Peter S. Cranston, Department of Entomology, University of California, Davis, CA, U.S.A., for helpful suggestions on paper writing.

Conflicts of Interest: The authors declare no conflict of interest.

\section{Appendix A}

Table A1. Primers used for polymerase chain reaction amplification and sequencing.

\begin{tabular}{cccc}
\hline Gene & Name & Sequence & Reference \\
\hline 18S rDNA & $18 \mathrm{~S}$ & CCTGAGAAACGGCTACCACATC & Whiting et al. (1997) [52] \\
18S rDNA & $18 \mathrm{~S}$ & GAGTCTCGTTCGTTATCGGA & Whiting et al. (1997) [52] \\
28S rDNA & S3660 & GAGAGTTMAASAGTACGTGAAAC & Morse and Normark (2006) [53] \\
28S rDNA & A335 & TCGGAAGGAACCAGCTACTA & Whiting et al. (1997) [52] \\
CAD1 & $54 \mathrm{~F}$ & GTNGTNTTYCARACNGGNATGGT & Moulton and Wiegmann (2004) [54] \\
CAD1 & 405R & GCNGTRTGYTCNGGRTGRAAYTG & Moulton and Wiegmann (2004) [54] \\
CAD4 & $787 \mathrm{~F}$ & GGDGTNACNACNGCNTGYTTYGARCC & Moulton and Wiegmann (2004) [54] \\
CAD4 & 1098R & TTNGGNAGYTGNCCNCCCAT & Moulton and Wiegmann (2004) [54] \\
COI-5P & LCO1490 & GGTCAACAAATCATAAAGATATTGG & Folmer et al. (1994) [55] \\
COI-5P & HCO2198 & TAAACTTCAGGGTGACCAAAAAATCA & Folmer et al. (1994) [55] \\
COI-3P & S2183 & CAACATTTATTTTGATTTTTTGG & Simon et al. (1994) [56] \\
COI-3P & A3014 & TCCAATGCACTAATCTGCCATATTA & Simon et al. (1994) [56] \\
\hline
\end{tabular}


Table A2. List of analyzed specimens with corresponding Genbank ID/ Bold ID and accession number.

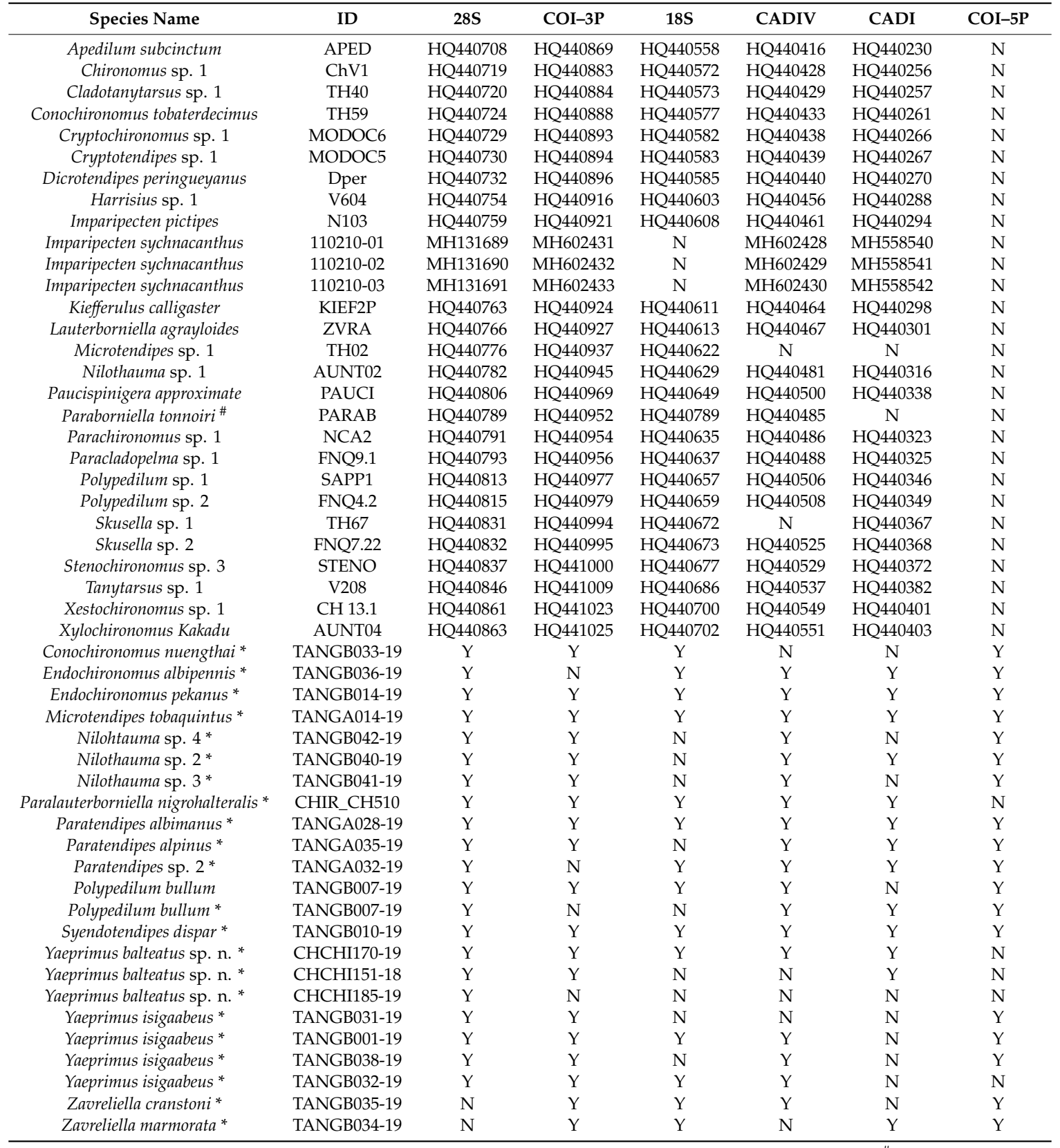

* sequences retrieved from Bold, ' $\mathrm{Y}$ ' means available, ' $\mathrm{N}$ ' means not available. Accession number of ${ }^{\#}$ sequence was renewed by Cranston for the same entries listed for Paraborniella as for Paralauterborniella in Table A1 from their work in 2012.

\section{References}

1. Sasa, M.; Suzuki, H. Stuidies on the chironomid species collected on Ishigaki and Iriomote Islands, Southwestern Japan. Trop. Med. 2000, 42, gz7.

2. Yamamoto, M.; Yamamoto, N. A review of Yaeprimus isigaabeus Sasa et Suzuki, 2000 (Diptera: Chironomidae), with taxonomic notes on the genera distributed in Yaeyama Island. In Proceedings of the 17th Intertional Symposium on Chironomidae, Nankai University, Tianjin, China, 6-10 July 2009; Wang, X.H., Liu, W., Eds.; Nankai University Press: Tianjin, China, 2009; pp. 224-239.

3. Cranston, P.S.; Hardy, N.B.; Morse, G.E. A dated molecular phylogeny for the Chironomidae (Diptera). Syst. Entomol. 2012, 37, 172-188. [CrossRef] 
4. Harrison, A.D. Four new genera and species of Chironomidae (Diptera) from southern Africa. Aquat. Insects 2000, 22, 219-236. [CrossRef]

5. Tang, H.Q.; Jinan University, Guangzhou, Guangdong, China; Helen, B.J. (Albany Museum, Grahamstown, South Africa). Personal communication, 2019.

6. Tang, H.Q.; Jinan University, Guangzhou, Guangdong, China; Martin, S. (Zoologische Staatssammlung München, Munich, Germany). Personal communication, 2019.

7. Tang, H.Q.; Jinan University, Guangzhou, Guangdong, China; Zhang, R.L. (Shanghai Ocean University, Shanghai, China); Lin, X.L. (Nankai University, Tianjin, China). Personal communication, 2019.

8. Tang, H.Q. Paralauterborniella from Oriental China (Diptera: Chironomidae). Orient. Insects 2016, 50, 160-170. [CrossRef]

9. Tang, H.Q.; Cranston, P.S. A new tribe in the Chironominae (Diptera: Chironomidae) validated by first immature stages of Xiaomyia Sæther \& Wang and a phylogenetic review. Raffles B. Zool. 2019, 67, 684-693. [CrossRef]

10. Wu, H.; Tang, H.Q. Phylogeny of marine Ainuyusurika tuberculata (Tokunaga) (Diptera: Chironomidae: Chironominae), with description of the immature stages. Zootaxa 2019, 4695, 131-147. [CrossRef]

11. Niitsuma, H.; Tang, H.Q. Taxonomic review of Ablabesmyia Johannsen (Diptera: Chironomidae: Tanypodinae) from Oriental China, with descriptions of six new species. Zootaxa 2019, 4564, 248-270. [CrossRef]

12. Cranston, P.S. Electronic Identification Guide to the Australian Chironomidae. Available online: http: //entomology/ucdavis.edu/chiropage/index.html (accessed on 30 October 2019).

13. Cranston, P.S.; Dillon, M.E.; Pinder, L.C.V.; Reiss, F. The adult males of Chironominae (Diptera: Chironomidae) of the Holarctic region-Keys and diagnoses. In Chironomidae of the Holarctic Region; Wiederholm, T., Ed.; Keys and Diagnoses, Part 3, Adult Males; Entomological Society of Lund: Lund, Sweden, 1989; Volume 34, pp. 353-502.

14. Langton, P.H. A Key to Pupal Exuaviae of West Palaearctic Chironomidae; P. Langton: Swanage, UK, 1991; pp. 222-311.

15. Saether, O.A. Glossary of chironomid morphology terminology (Diptera: Chironomidae). Entomol. Scand. 1980, 14, 1-51.

16. Cranston, P.S. Riethia (Kieffer 1917)(Diptera: Chironomidae) revised for the Austro-Pacific region. Zootaxa 2019, 4646, 461-500. [CrossRef]

17. Epler, J.H. Biosystematics of the genus Dicrotendipes Kieffer, 1913 (Diptera: Chironomidae) of the world. Mem. Am. Entomol. Soc. 1988, 36, 1-214.

18. Lin, X.L.; Stur, E.; Ekrem, T. Molecular phylogeny and temporal diversification of Tanytarsus van der Wulp (Diptera: Chironomidae) support generic synonymies, a new classification and centre of origin. Syst. Entomol. 2018, 43, 659-677. [CrossRef]

19. Lin, X.L.; Stur, E.; Ekrem, T. Exploring species boundaries with multiple genetic loci using empirical data from non-biting midges. Zool. Scr. 2018, 47, 325-341. [CrossRef]

20. Lin, X.L.; Stur, E.; Ekrem, T. DNA barcodes and morphology reveal unrecognized species in Chironomidae (Diptera). Insect. Syst. Evol. 2017, 49, 329-398. [CrossRef]

21. Hebert, P.D.N.; Ratnasingham, S.; De Waard, J.R. Barcoding animal life: Cytochrome c oxidase subunit 1 divergences among closely related species. Proc. Biol. Sci. 2003, 270 (Suppl. 1), S96-S99. [CrossRef]

22. Edgar, R.C. MUSCLE: Multiple sequence alignment with improved accuracy and speed. In Proceedings of the 2004 IEEE Computational Systems Bioinformatics Conference, Stanford, CA, USA, 19 August 2004; IEEE: Piscataway, NJ, USA, 2004; pp. 728-729. [CrossRef]

23. Kumar, S.; Stecher, G.; Tamura, K. MEGA7: Molecular Evolutionary Genetics Analysis Version 7.0 for Bigger Datasets. Mol. Biol. Evol. 2016, 33, 1870-1874. [CrossRef]

24. Rogers, J.; Wall, R. A mechanism for RNA splicing. Proc. Natl. Acad. Sci. USA 1980, 77, 1877-1879. [CrossRef]

25. Castresana, J. Selection of conserved blocks from multiple alignments for their use in phylogenetic analysis. Mol. Biol. Evol. 2000, 17, 540-552. [CrossRef]

26. Talavera, G.; Castresana, J. Improvement of phylogenies after removing divergent and ambiguously aligned blocks from protein sequence alignments. Syst. Biol. 2007, 56, 564-577. [CrossRef]

27. Zhang, D.; Gao, F.; Li, W.; Jakovlić, I.; Zou, H.; Zhang, J.; Wang, G.T. PhyloSuite: An integrated and scalable desktop platform for streamlined molecular sequence data management and evolutionary phylogenetics studies. Mol. Ecol. Resour. 2018. [CrossRef] 
28. Lanfear, R.; Calcott, B.; Ho, S.Y.W.; Guindon, S. PartitionFinder: Combined Selection of Partitioning Schemes and Substitution Models for Phylogenetic Analyses. Mol. Biol. Evol. 2012, 29, 1695-1701. [CrossRef]

29. Nguyen, L.T.; Schmidt, H.A.; von Haeseler, A.; Minh, B.Q. IQ-TREE: A fast and effective stochastic algorithm for estimating maximum-likelihood phylogenies. Mol. Biol. Evol. 2014, 32, 268-274. [CrossRef] [PubMed]

30. Ronquist, F.; Teslenko, M.; van der Mark, P.; Ayres, D.L.; Darling, A.; Hohna, S.; Larget, B.; Liu, L.; Suchard, M.A.; Huelsenbeck, J.P. MrBayes 3.2: Efficient Bayesian phylogenetic inference and model choice across a large model space. Syst. Biol. 2012, 61, 539-542. [CrossRef]

31. Rambaut, A.; Suchard, M.A.; Xie, D.; Drummond, A.J. Tracer v1.6. Available online: http://beast.bio.ed.ac.uk/ Tracer (accessed on 30 October 2019).

32. Ratnasingham, S.; Hebert, P.D.N. BOLD: The Barcode of Life Data System (http://www/. barcodinglife. org). Mol. Ecol. Notes 2007, 7, 355-364. [CrossRef] [PubMed]

33. Ratnasingham, S.; Hebert, P.D.N. A DNA-Based Registry for All Animal Species: The Barcode Index Number (BIN) System. PLoS ONE 2013, 8, e66213. [CrossRef] [PubMed]

34. Maguire, D.J. ArcGIS: General purpose GIS software system. Encycl. GIS 2008, 25-31.

35. Sæther, O.A. Female Genitalia in Chironomidae and Other Nematocera: Morphology, Phylogenies, Keys; Stevenson, J.C., Ed.; Bulletin of the Fisheries Research Board of Canada: Ottawa, ON, Canada, 1997; p. 139.

36. Huang, D.W.; Cheng, L.N. The flightless marine midge Pontomyia (Diptera: Chironomidae): Ecology, distribution, and molecular phylogeny. Zool. J. Linn. Soc. 2011, 162, 443-456. [CrossRef]

37. Lin, X.L.; Qi, X.; Zhang, R.L.; Wang, X.H. A new species of Polypedilum (Uresipedilum) Oyewo \& Sæther, 1998 from Zhejiang Province of Oriental China (Diptera, Chironomidae). Zookeys 2013, 320, 43-49. [CrossRef]

38. Yamamoto, M.; Yamamoto, N.; Tang, H.Q. Two new chironomids bearing peculiar morphological features from Japan and China (Diptera: Chironomidae). J. Limnol. 2018, 77, 40-49. [CrossRef]

39. Tang, H.Q.; Jinan University, Guangzhou, Guangdong, China; Yamamoto, M. (Kankyou-kagakuK abushiki-gaisha, Naka-sakurazuka, Toyonaka, Osaka, Japan). Personal communication, 2018.

40. Zorina, O.V. Non-biting midges of the genus Paracladopelma Harnisch (Diptera: Chironomidae) from the Russian Far East. Zootaxa 2006, 1134, 29-49. [CrossRef]

41. Donato, M.; Paggi, A.C.; Epler, J.H. New record, geographic variation and redescription of Apedilum elachistus Townes (Diptera: Chironomidae: Chironominae). Stud. Neotrop. Fauna. E. 2008, 43, 125-134. [CrossRef]

42. Epler, J.H. A reconsideration of the genus Apedilum Townes, 1945. Spixiana 1988, 14, 105-116.

43. Pinho, L.C.; Mendes, H.F.; Andersen, T. Revision of Beardius Reiss et Sublette, 1985 (Diptera: Chironomidae), with the description of twenty new species. Zootaxa 2013, 3742, 1-78. [CrossRef] [PubMed]

44. Grodhaus, G. Endochironomus Kieffer, Tribelos Townes, Synendotendipes, n. gen., and Endotribelos, n. gen.(Diptera: Chironomidae) of the Nearctic region. J. Kansas Entomol. Soc. 1987, 60, 167-247.

45. Silva, F.L. Procladius travassosi (Oliveira, Messias Silva-Vasconcelos, 1992) regarded as a new junior synonym of Procladius stroudi Roback 1982 (Diptera: Chironomidae: Tanypodinae). Zootaxa 2019, 4555, 280-282. [CrossRef] [PubMed]

46. Niitsuma, H. A New Species of the Genus Coffmania (Insecta: Diptera: Chironomidae) from Japan. Species Divers. 2008, 13, 123-131. [CrossRef]

47. Wiedenbrug, S.; Andersen, T. New Species of Parakiefferiella Thienemann, 1936 from South America (Chironomidae, Orthocladiinae). Stud. Neotrop. Fauna Environ. 2002, 37, 119-132. [CrossRef]

48. Cranston, P.S.; Saether, O.A. Rheosmittia (Diptera: Chironomidae): A generic validation and revision of the western Palaerctic species. J. Nat. Hist. 1986, 20, 31-51. [CrossRef]

49. Reiss, F. Irmakia, ein neues Subgenus von Demicryptochironomus LENZ, 1941. mit der Beschreibung von vier neuen Arten (Diptera, Chironomidae). Spixiana 1988, 11, 1-12.

50. Cranston, P.S.; Martin, J.; Spies, M. Cryptic species in the nuisance midge Polypedilum nubifer (Skuse (Diptera: Chironomidae) and the status of Tripedilum Kieffer. Zootaxa 2016, 4079, 429-447. [CrossRef]

51. Fusari, L.M.; Dantas, G.P.; Hamada, N.; Andrade-Souza, V.; Lima, K.M.; Silva, J.G. Not endemic after all: Imparipecten Freeman, 1961 (Diptera: Chironomidae) described from the Neotropical Region. Zootaxa 2018, 4532, 396-406. [CrossRef]

52. Whiting, M.F.; Carpenter, J.C.; Wheeler, Q.D.; Wheeler, W.C. The Strepsiptera problem: Phylogeny of the holometabolous insect orders inferred from $18 \mathrm{~S}$ and $28 \mathrm{~S}$ ribosomal DNA sequences and morphology. Syst. Biol. 1997, 46, 1-68. [CrossRef] [PubMed] 
53. Morse, G.E.; Normark, B.B. A molecular phylogenetic study of armoured scale insects (Hemiptera: Diaspididae). Syst. Entomol. 2006, 31, 338-349. [CrossRef]

54. Moulton, J.K.; Wiegmann, B.M. Evolution and phylogenetic utility of CAD (rudimentary) among Mesozoic-aged Eremoneuran Diptera (Insecta). Mol. Phylogenet. Evol. 2004, 31, 363-378. [CrossRef]

55. Folmer, O.; Black, M.; Hoeh, W.; Lutz, R.; Vrijenhoek, R. DNA primers for amplification of mitochondrial cytochrome c oxidase subunit I from diverse metazoan invertebrates. Mol. Mar. Biol. Biotechnol. 1994, 3, 294-299.

56. Simon, C.; Frati, F.; Beckenbach, A.; Crespi, B.; Liu, H.; Flook, P. Evolution, weighting, and phylogenetic utility of mitochondrial gene sequences and a compilation of conserved polymerase chain reaction primers. Ann. Entomol. Soc. Am. 1994, 87, 651-701. [CrossRef]

(C) 2020 by the authors. Licensee MDPI, Basel, Switzerland. This article is an open access article distributed under the terms and conditions of the Creative Commons Attribution (CC BY) license (http://creativecommons.org/licenses/by/4.0/). 